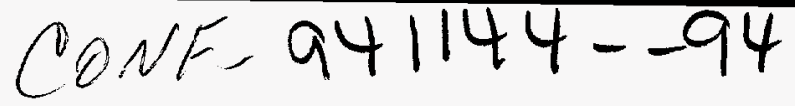

\title{
APPLICATIONS OF SXPS FOR STUDYING SURFACE STRUCTURE, REACTION MECHANISMS AND KINETICS
}

\author{
D. R. MULLINS, D. R. HUNTLEY AND S. H. OVERBURY \\ Oak Ridge National Laboratory, PO Box 2008, Oak Ridge, TN 37831-6201
}

\begin{abstract}
Soft x-ray photoelectron spectroscopy (SXPS) from the S $2 p$ core level has been used to study adsorbate induced reconstruction, identify reaction intermediates and study reaction kinetics on the Ni(111) surface. The $\mathrm{S} 2 p$ binding energy is affected by the nature of the surface adsorption site. It has been determined from the number of $S 2 p$ states and their relative binding energies that adsorbed $\mathrm{S}$ induces a reconstruction of the $\mathrm{Ni}(111)$ surface and that the $\mathrm{S}$ adsorbs in fourfold sites on terraces and in troughs. S $2 p$ SXPS has also been used to identify adsorbed species during the thermal decomposition of methanethiol on $\mathrm{Ni}(111)$. $\mathrm{CH}_{3} \mathrm{SH}$ adsorbs as $\mathrm{CH}_{3} \mathrm{~S}-$ at low temperatures. Above $200 \mathrm{~K}$, the $\mathrm{CH}_{3} \mathrm{~S}$ - changes adsorption site and the $\mathrm{C}-\mathrm{S}$ bond begins to cleave. The relative concentrations of $\mathrm{CH}_{3} \mathrm{~S}$ - in the two different sites and of atomic $\mathrm{S}$ have been monitored as a function of temperature and initial coverage. As a result of the sensitivity and resolution available in SXPS, reactions rates and kinetic parameters have been obtained for the decomposition of benzenethiol on $\mathrm{Ni}(111)$ by monitoring the changes in the surface composition continuously as a function of temperature and time.
\end{abstract}

\section{INTRODUCTION}

The study of the surface chemistry of $S$ and $S$ containing molecules is important for establishing an understanding of materials such as sulfide catalysts, the reactivity of $S$ containing pollutants and characterizing $\mathrm{S}$ based antiwear films. Soft $\mathrm{x}$-ray photoelectron spectroscopy (SXPS) of the S $2 p$ core level has been developed as a very sensitive tool for studying these systems. $200-300 \mathrm{eV}$ excitation from a synchrotron light source results in at least an order of magnitude improvement in sensitivity coupled with a $2-3$ times improvement in resolution for the S $2 p$ signal compared to traditional XPS excited using a laboratory anode source.

It was observed in a study of $S$ on W(001) that despite having the same nominal emitting species on the surface, i. e. atomic $\mathrm{S}$, a number of $\mathrm{S} 2 p$ core level states were observed as a function of coverage.[1] It was concluded that the $S 2 p$ binding energy is influenced by the nature of the surface adsorption site and, further, that binding energy decreases as the coordination of the adsorption site decreases. This observation was extended to molecular adsorbates with the observation that methyl thiolate, $\mathrm{CH}_{3} \mathrm{~S}$-, produces a number of $\mathrm{S} 2 p$ states on $\mathrm{W}(001)$ and $\mathrm{Ru}(0001)$ presumably due to adsorption in different sites.[2,3]

In this paper we will summarize recent experiments that were conducted to determine the structure and reactivity of $\mathrm{S}$ and $\mathrm{S}$ containing molecules on Ni(111). The $\mathrm{S} 2 p$ SXPS has demonstrated that the reconstruction of $\mathrm{Ni}(111)$ that occurs at high $\mathrm{S}$ coverages results in new $\mathrm{S}$ adsorption sites that have a higher coordination than the three-fold site that is favored at low coverages. $\mathrm{CH}_{3} \mathrm{~S}$ - changes adsorption site as the sample is heated, moving from a bridge site to a hollow site as the temperature is raised from $100-250 \mathrm{~K}$. Finally, the cleavage of the $\mathrm{C}-\mathrm{S}$ bond in phenylthiolate, $\mathrm{C}_{6} \mathrm{H}_{5} \mathrm{~S}$-, was monitored as a function of time at constant temperature. 


\section{DISCLAIMER}

Portions of this document may be illegible in electronic image products. Images are produced from the best available original document. 
Reaction rates were derived from these experiments that aid in the determination of the reaction mechanism and the activation energy for the bond cleavage reaction.

\section{STRUCTURE}

Numerous experiments have established that adsorbed $\mathbf{S}$ produces a reconstruction of the $\mathrm{Ni}(111)$ surface at coverages between $0.3-0.4 \mathrm{ML}\left(1 \mathrm{ML}=1.86 \times 10^{15} \mathrm{~cm}^{-2}\right)$. The nature of this reconstruction has now been firmly established. It was determined by ion scattering [4] and SEXAFS [5] that the $\mathbf{S}$ adatoms adsorb in three-fold hollow sites at low coverage. At higher coverage it was concluded that the close-packed structure of the first Ni layer was disrupted and that the coordination of the $\mathrm{S}$ adsorption site was increased. STM images indicated a terrace and trough configuration for the $\mathrm{Ni}$ atoms following reconstruction [6] and a terrace structure composed of rotated $\mathrm{Ni}$ tetramers was proposed based on glancing incidence $\mathrm{x}$-ray scattering.[7]

The S $2 p$ SXPS from S adsorbed at different coverages on Ni(111) is shown in Fig. 1. At coverages below $0.25 \mathrm{ML}$ a single $\mathrm{S} 2 p$ doublet is observed with a $\mathrm{S} 2 p_{3 / 2}$ peak position of $161.14 \mathrm{eV}$. This peak is assigned to $\mathrm{S}$ adsorbed in a three-fold hollow site as shown on the lower right side of the figure. Near the saturation coverage of $0.4 \mathrm{ML}$ two new $\mathrm{S} 2 p$ states are readily identified with $\mathrm{S} 2 p_{3 / 2}$ binding energies of $161.54 \pm \mathrm{eV}$ and $162.07 \mathrm{eV}$.

Fig. $1 \mathrm{~S} 2 p$ photoemission spectra from atomic $\mathrm{S}$ adsorbed on $\mathrm{Ni}(111)$

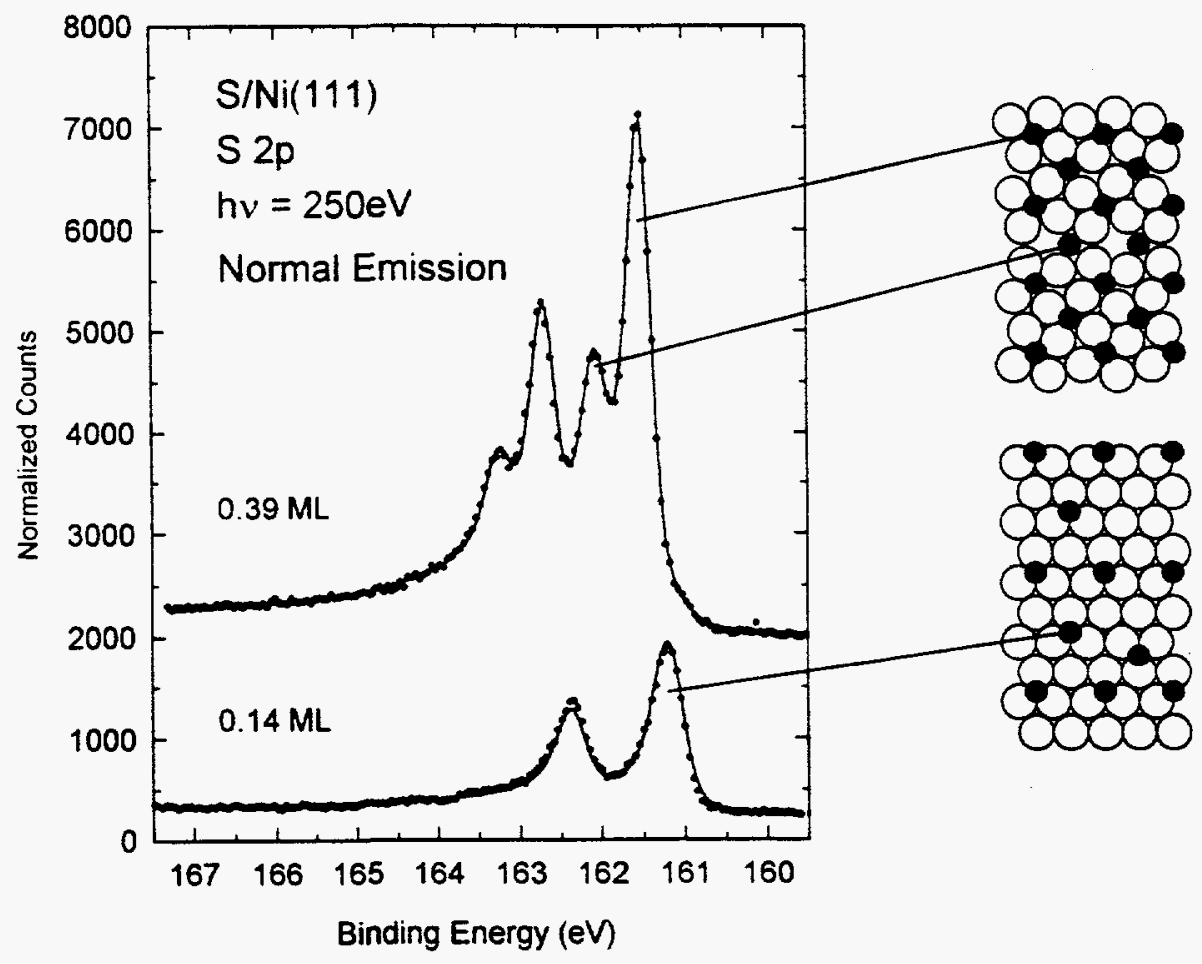

These spectra establish that: 1) there are three different adsorption states for $\mathrm{S}$ on $\mathrm{Ni(111)}$ as a function of coverage, 2) neither of the two states that result at high coverage are from $S$ adsorbed in a threefold site and 3) there is more $\mathrm{S}$ in the $161.54 \mathrm{eV}$ state than in the $162.07 \mathrm{eV}$ state. The increase in binding energy that occurs following reconstruction indicates that the coordination of the $\mathrm{S}$ adsorption site has increased compared to the three-fold coordination that occurs at low coverage. This conclusion is supported by vibrational spectra that show a decrease in the S - Ni stretching frequency at high S coverage.[8] The model proposed on the basis of glancing incidence $\mathrm{X}$-ray scattering is shown on the upper right of Fig.1.[7] Based on the relative 
intensities, the $161.54 \mathrm{eV}$ state is assigned to the $\mathrm{S}$ atoms adsorbed in the center of the $\mathrm{Ni}$ tetramers that comprise the terraces, and the $162.07 \mathrm{eV}$ state is assigned to $\mathrm{S}$ adsorbed in the troughs between the terraces. Sulfur is bonded to four Ni atoms in both types of sites, suggesting that even relatively small structural differences can result in significant $\mathrm{S} 2 p$ binding energy shifts.

\section{REACTIONS OF S CONTAINING MOLECULES}

\section{Identification of Surface Intermediates}

Methanethiol, $\mathrm{CH}_{3} \mathrm{SH}$, reacts with $\mathrm{Ni}(111)$ at $100 \mathrm{~K}$ to form methyl thiolate, $\mathrm{CH}_{3} \mathrm{~S}$-. Methyl thiolate then reacts at higher temperatures to produce either $\mathrm{S}$ and desorbed $\mathrm{CH}_{4}$, or $\mathrm{S}, \mathrm{C}$, and desorbed $\mathrm{H}_{2}$. The $\mathrm{S} 2 p$ spectrum from $0.25 \mathrm{ML}$ of $\mathrm{CH}_{3} \mathrm{~S}$ - adsorbed on $\mathrm{Ni}(111)$ at $100 \mathrm{~K}$ is shown in Fig. 2. A lone doublet is observed at $150 \mathrm{~K}$ with a $\mathrm{S} 2 p_{3 / 2}$ binding energy of 162.20 $\mathrm{eV}$. At $250 \mathrm{~K}$ the $162.20 \mathrm{eV}$ state has diminished in intensity and two new states appear at lower binding energy, $161.55 \mathrm{eV}$ and $161.10 \mathrm{eV}$, and one state at higher binding energy, $163.30 \mathrm{eV}$. The low binding energy states are assigned to atomic $S$. This assignment is based on a comparison with the binding energies for atomic $S$ adsorbed on clean Ni(111).(see Fig. 1) The $161.10 \mathrm{eV}$ state is the same as $\mathrm{S}$ adsorbed in the three-fold hollow site. The intensity of the $161.55 \mathrm{eV}$ state correlates with the amount of atomic $\mathrm{C}$ observed in the $\mathrm{C} 1 \mathrm{~s}$. It isn't clear whether this state represents a bonding interaction between $\mathrm{C}$ and $\mathrm{S}$ or whether the $\mathrm{C}$ and $\mathrm{S}$ produce a reconstruction of the $\mathrm{Ni}(111)$ surface. The $163.30 \mathrm{eV}$ state is assigned to methyl thiolate that has shifted from a bridge adsorption site to a hollow adsorption site. This

Fig. 2 - S $2 p$ photoemission from 0.25 $\mathrm{ML}$ of $\mathrm{CH}_{3} \mathrm{~S}$ - adsorbed on $\mathrm{Ni}(111)$ at $100 \mathrm{~K}$ using $250 \mathrm{eV}$ excitation and normal emission.

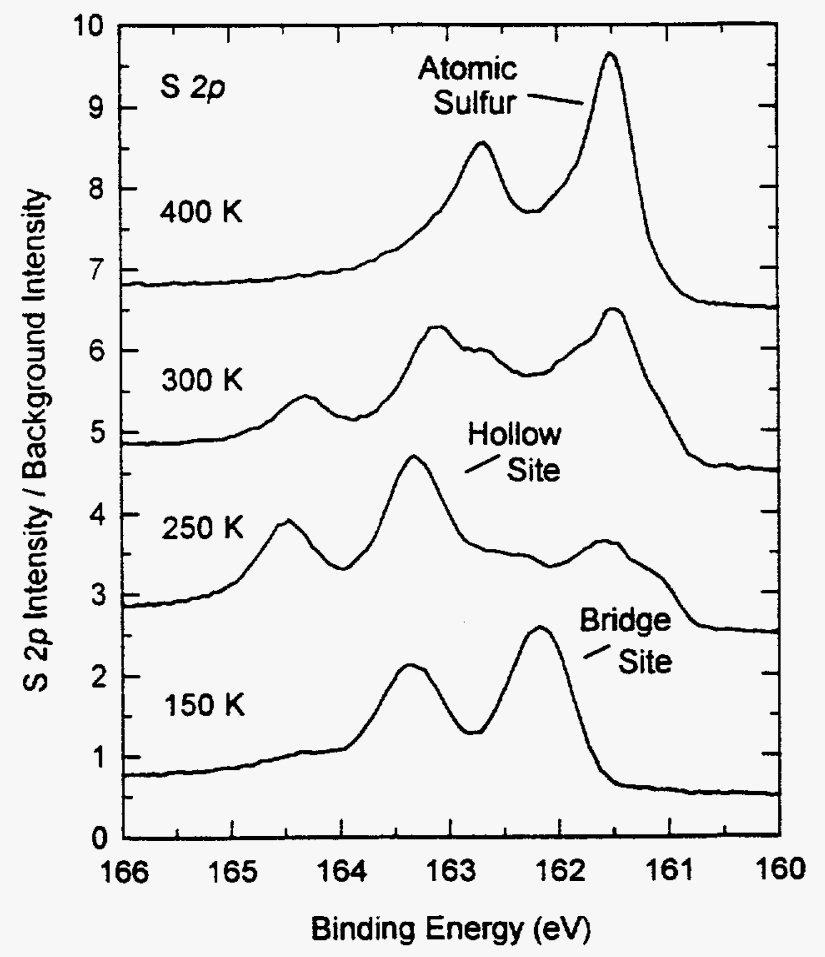

assignment is consistent with HREELS data that indicate no new molecular species appearing between $150-300 \mathrm{~K}$.[9] At $300 \mathrm{~K}$ the $\mathrm{S} 2 p$ intensity from methyl thiolate in the hollow site 
decreases as the thiolate begins to decompose. At $400 \mathrm{~K}$ all of the molecular species have disappeared and the spectrum is dominated by the signal from atomic $\mathrm{S}$ associated with atomic C. The amount of unperturbed atomic sulfur at $161.10 \mathrm{eV}$ is greatly diminished at $400 \mathrm{~K}$ as the atomic $\mathrm{C}$ builds up on the surface as a result of total decomposition.

\section{Thermal Stability of Intermediates}

The cleavage of the $\mathrm{C}-\mathrm{S}$ bond producing atomic $\mathrm{S}$, and the formation and subsequent disappearance of methyl thiolate bonded in a hollow site can be seen as a function of temperature in the temperature programmed SXPS data shown in Fig. 3. These curves were recorded by monitoring the $\mathrm{S} 2 p_{3 / 2}$ intensity of atomic $\mathrm{S}$ at $161.55 \mathrm{eV}$ and the $\mathrm{S} 2 p_{1 / 2}$ intensity of the hollow site bonded thiolate at $164.50 \mathrm{eV}$ as a function of sample temperature. The initial decrease in hollow site bonded signal is due to the desorption of multilayer methanethiol whose

Fig. 3 - Temperature programmed SXPS spectra of the $\mathrm{S} 2 p$ core levels from atomic $S$ and methyl thiolate adsorbed in a hollow site for $\mathrm{CH}_{3} \mathrm{SH}$ adsorbed on $\mathrm{Ni}(111)$ at $100 \mathrm{~K}$.

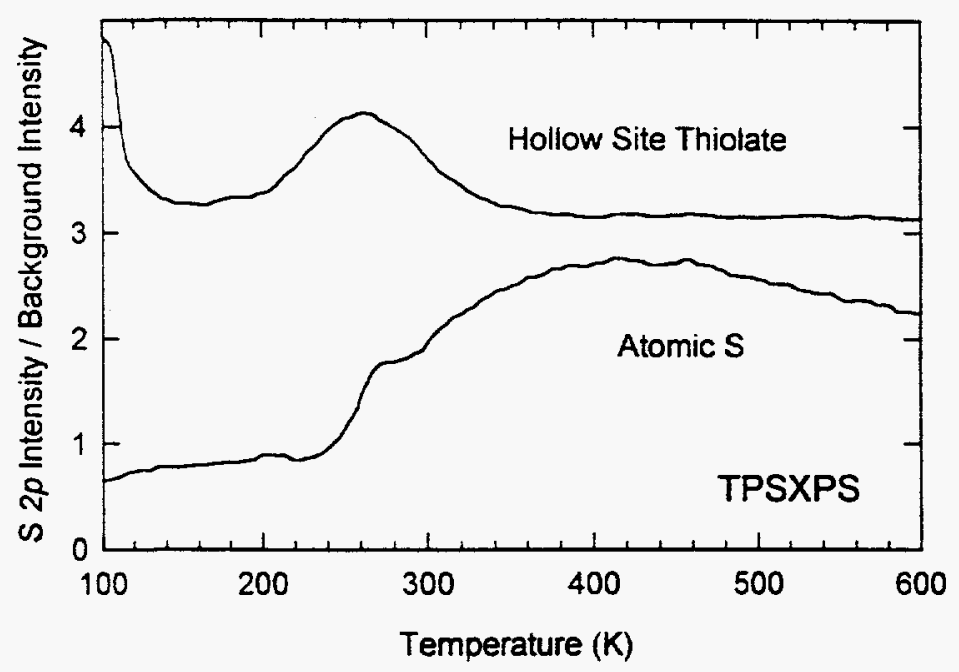

$\mathrm{S} 2 p_{3 / 2}$ peak overlaps with the methyl thiolate $\mathrm{S} 2 p_{1 / 2}$ peak. The signal from the thiolate in the hollow - site starts to increase and reaches a maximum near $260 \mathrm{~K}$ indicating the conversion of thiolate from the bridge to the hollow site. The atomic S signal starts to increase near $240 \mathrm{~K}$, levels off around $260 \mathrm{~K}$ and then increases again at $290 \mathrm{~K}$. The initial increase in atomic $\mathrm{S}$ is due to the decomposition of methyl thiolate in the bridge site. The second increase in atomic $\mathrm{S}$, near $290 \mathrm{~K}$, stems from the decomposition of the hollow site thiolate. This further demonstrates that the thiolate in the hollow site is more stable than the thiolate in the bridge site. The decrease in the atomic $S$ signal above $450 \mathrm{~K}$ can be correlated with the loss of atomic $\mathrm{C}$ through diffusion into the bulk, which results in a shift of the atomic $S$ signal from $161.55 \mathrm{eV}$ to $161.10 \mathrm{eV}$.

The stability of the methyl thiolate in the bridge site is coverage dependant. Fig. 4 shows temperature programmed SXPS data from three different coverages of $\mathrm{CH}_{3} \mathrm{~S}-$. At $0.08 \mathrm{ML}$ the onset of $\mathrm{C}-\mathrm{S}$ bond scission is at $150 \mathrm{~K}$. At $0.25 \mathrm{ML}$ the onset is near $240 \mathrm{~K}$, and at $0.15 \mathrm{ML}$ there are two steps at $150 \mathrm{~K}$ and $240 \mathrm{~K}$. The bridge bonded thiolate's $\mathrm{S} 2 p_{3 / 2}$ binding energy shifts from $162.60 \mathrm{eV}$ to $162.20 \mathrm{eV}$ between 0.08 and $0.25 \mathrm{ML}$. At $0.15 \mathrm{ML}$ both states are evident. The shift in binding energy and the relative stability at low and high coverage are presumably the result of crowding in the thiolate overlayer. 
Fig. 4 - Temperature programmed SXPS spectra from three diffent coverages of $\mathrm{CH}_{3} \mathrm{~S}$ - on $\mathrm{Ni}(111)$ showing the decomposition of bridge bonded thiolate producing atomic S.

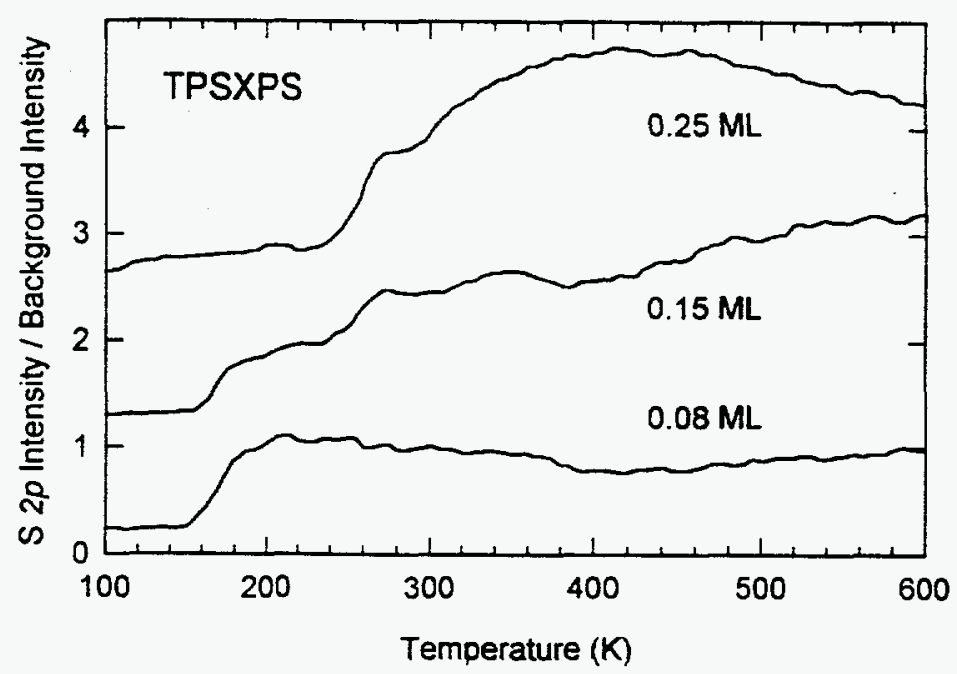

\section{$\underline{\text { Reaction Kinetics }}$}

The rate of $\mathrm{C}-\mathrm{S}$ bond scission at different temperatures during the decomposition of phenylthiolate, $\mathrm{C}_{5} \mathrm{H}_{5} \mathrm{~S}$-, on $\mathrm{Ni}(111)$ was determined by recording the increase in the atomic $\mathrm{S}$ signal as a function of time at constant temperature.(Fig. 5) The decomposition of phenylthiolate is simpler than the decomposition of methyl thiolate because only one form of atomic $S$ is produced and the phenyl thiolate does not shift to a different adsorption site, therefore there is only one reaction pathway that needs to be considered. The solid lines in Fig. 5 indicate a fit to the data using a rate law that is second order in phenyl thiolate concentration. There was generally better agreement using a second order rate law than a first order rate law. This second

Fig. 5 - S $2 p$ photoemission intensity from atomic sulfur during isothermal anneals of $\mathrm{C}_{6} \mathrm{H}_{5} \mathrm{~S}$ - at the indicated temperatures. Fits using a second order rate law are also shown.

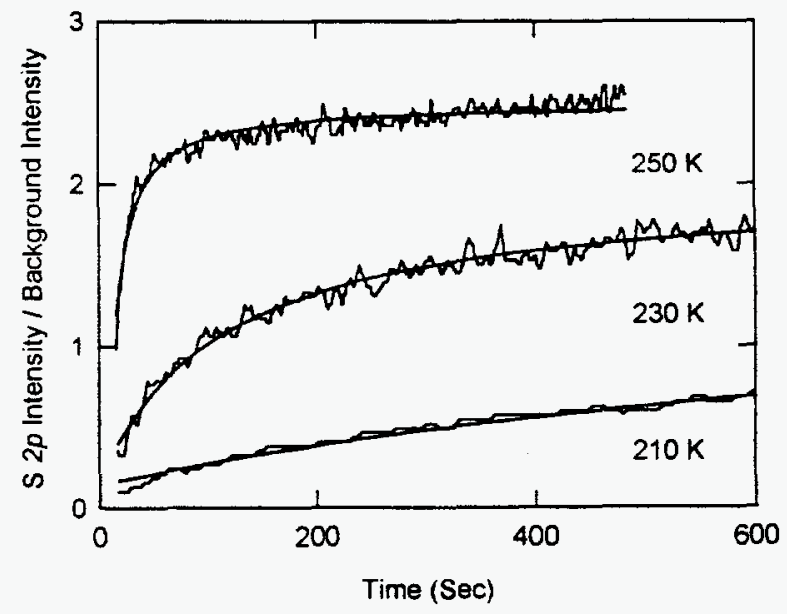

order dependance can be rationalized through a decomposition mechanism in which adsorbed $\mathrm{H}$ atoms participate in the rate determining step of the $\mathrm{C}-\mathrm{S}$ bond cleavage reaction.[10] The reaction is therefore first order in phenyl thiolate and first order in $\mathrm{H}$. It appears to be second order in phenyl thiolate because the adsorbed $\mathrm{H}$ comes from the sulfhydryl $\mathrm{H}$ of parent benzenethiol adsorbate and therefore the thiolate and the $\mathrm{H}$ concentrations are the same. The activation energy for this reaction is $10 \mathrm{kcal} /$ mole based on an Arrhenius plot of the rate 
constants. This value is smaller than might be expected for a reaction occurring around $240 \mathrm{~K}$ and may be related to $\mathrm{H}$ assistance in the bond cleavage reaction.

\section{SUMMARY}

Soft x-ray photoelectron spectroscopy from the $\mathrm{S} 2 p$ core level has been shown to be an extremely powerful tool for studying surface structure, adsorbate reactions and reaction kinetics. In principle, SXPS should also be very useful for studying other core levels. In particular, the $2 p$ levels of $\mathrm{P}$ and $\mathrm{Cl}$ should behave similarly. The $\mathrm{S} 2 p$ level has been particularly advantageous because it has a relatively narrow natural linewidth (ca. $0.15 \mathrm{eV}$ ). The $1 s$ levels of $\mathrm{C}$, $\mathrm{N}$, and $\mathrm{O}$ have been shown to be much broader and may limit the advantages realized using SXPS to study these species.[11]

Research sponsored by the Division of Chemical Sciences, Office of Basic Energy Sciences, U.S. Department of Energy under contract DE-AC05-84OR21400 with Martin Marietta Energy Systems, Inc. The National Synchrotron Light Source at Brookhaven National Laboratory is supported by the Division of Chemical Sciences and Division of Material Sciences of the U. S. Department of Energy under contract DE-AC02-76CH00016.

\section{REFERENCES}

[1] D. R. Mullins, P. F. Lyman and S. H. Overbury, Surface Sci., 277, 64 (1992).

[2] D. R. Mullins and P. F. Lyman, J. Phys. Chem., 97, 9226 (1993).

[3] D. R. Mullins and P. F. Lyman, J. Phys. Chem., 97, 12008 (1993).

[4] Y.-S. Ku and S. H. Overbury, Surf. Sci., 276, 262 (1992).

[5] D. R. Warburton, P. L. Wincott, G. Thornton, F. M. Quinn and D. Norman, Surf. Sci., 211/212, 71 (1989); Y. Kitama, T. Yokoyama, T. Ohta, M. Funabashi, N. Kosugi and H. Kuroda, ibid., 214, L261 (1989).

[6] L. Ruan, I. Stensgaard, F. Besenbacher and E. Lægsgaard, Phys. Rev. Lett., 71, 2963 (1993).

[7] M. Foss, R. Feidenhans'l, M. Nielsen, E. Findeisen, R. L. Johnson, T. Buslaps, I.Stensgaard and F. Besenbacher, Phys. Rev. B, 50, 8950 (1994).

[8] D. R. Mullins, D. R. Huntley and S. H. Overbury, Surface Sci., in press.

[9] T. S. Rufael, D. R. Mullins, J. L. Gland and D. R. Huntley, J. Phys. Chem., Submitted. [10] D. R. Huntley, J. Phys. Chem., 96, 4550 (1992).

[11] N. Mårtensson and A. Nilsson, J. Electron Spectrosc. Relat. Phenom., 52, 1 (1990).

\section{DISCLAIMER}

\footnotetext{
This report was prepared as an account of work sponsored by an agency of the United States Government. Neither the United States Government nor any agency thereof, nor any of their employees, makes any warranty, express or implied, or assumes any legal liability or responsibility for the accuracy, completeness, or usefulness of any information, apparatus, product, or process disclosed, or represents that its use would not infringe privately owned rights. Reference herein to any specific commercial product, process, or service by trade name, trademark, manufacturer, or otherwise does not necessarily constitute or imply its endorsement, recommendation, or favoring by the United States Government or any agency thereof. The views and opinions of authors expressed herein do not necessarily state or reflect those of the United States Government or any agency thereof.
} 